\title{
LONGEVIDADE, ALIMENTOS DO INTERIOR DE MINAS GERAIS E NUTRIENTES ESSENCIAIS
}

\author{
LONGEVITY, FOOD FROM THE INTERIOR OF MINAS GERAIS AND ESSENTIAL \\ NUTRIENTS
}

\author{
Alexandre Calazans Guedes \\ Graduando, Faculdade Presidente Antônio Carlos, Brasil \\ E-mail: alexandrec guedes@hotmail.com \\ Pedro Emílio Salomão \\ Universidade Presidente Antônio Carlos, Brasil \\ E-mail: pedroemilioamador@yahoo.com.br \\ Recebido: 14/04/2021 - Aceito: 14/04/2021
}

\section{RESUMO}

Viver até uma idade avançada com qualidade de vida é um assunto que aborda várias vertentes. Cada pessoa possui um organismo único, o qual responderá a estímulos por toda a vida. Viver bem e com qualidade, alcançando a longevidade com saúde plena, acredita-se que é um grande desejo do ser humano e para isso, algumas questões básicas devem ser estabelecidas para que o organismo responda bem a esses estímulos. A alimentação saudável, seguindo um planejamento dietético com os nutrientes essenciais, macronutrientes e micronutrientes, associados à atividade física, é um fator chave para que o organismo funcione adequadamente. Uma alimentação rica em vegetais, fibras, antioxidantes, probióticos, entre outros, está associado diretamente à longevidade, pois atuam diretamente na prevenção de doenças.

Palavras-chave: Longevidade; macronutrientes; micronutrientes; antioxidantes; probióticos.

\begin{abstract}
Living to an advanced age with quality of life is a subject that addresses several aspects. Each person has a unique organism to which they will respond to stimuli throughout their lives. To live well and with quality, reaching longevity with full health, it is believed that it is a great desire of the human being and for that, some basic questions must be established so that the organism responds well to these stimuli. Healthy eating, following a dietary plan with essentials nutrients, macronutrients and micronutrients, associated with physical activity, is a key factor for the body function properly. A diet rich in vegetables, fibers, antioxidants, probiotics, among others, is directly associated with longevity, as they act directly in the prevention of diseases.
\end{abstract}

Key Words: Longevity; macronutrients; micronutrientes; antioxidants; probiotics. 


\section{Introdução}

Estamos em uma era moderna, onde o ser humano possuí informações e acesso a recursos que determinam o quão saudável pode ser. Além disso, esses fatores bem distribuídos em um padrão de vida equilibrado, podem aumentar gradativamente a longevidade do indivíduo (Kempinski et. Al., 2018).

Segundo Ferreira, (2010) Os alimentos processados e ultraprocessados ganharam peso no mercado. Produtos prontos e entregues à mão do consumidor de forma rápida e que oferecem um paladar bem degustativo, vem sendo consumidos por um grande número de pessoas (Ferreira, 2010). Segundo a World Health Organization, (2003), o processo tecnológico que facilitou a vida das pessoas, em muitos recursos, também teve uma resposta contrária em outros: diminuiu o número de doenças epidemiológicas que vinham muitas vezes do meio externo e aumentaram as doenças crônicas degenerativas, causadas na maioria dos casos por maus hábitos, sejam eles alimentares, falta de atividade física, uso abusivo de substâncias tóxicas e exposição ao estresse diário.

O envelhecimento é algo inevitável a todos e à medida que isso vai acontecendo, o organismo reduz a capacidade de combater algumas doenças, exemplo disso são as crônicas como diabetes, obesidade, hipertensão e hipercolesterolemia. Para que o corpo consiga manter um bom funcionamento fisiológico é imprescindível uma alimentação saudável, seguida também de bons hábitos (Guimarães e Oliveira, 2014).

Como Hipócrates já dizia, "deixe que o alimento seja seu remédio", esse pensamento nos mostra que não é somente em tempos modernos que essa ideologia já é usada. Segundo Brasil, (2006) para uma alimentação saudável é necessário um equilíbrio entre os nutrientes necessários para o bom funcionamento do organismo, sejam eles as proteínas, os carboidratos, lipídeos, fibras, vitaminas e minerais, sendo estes essenciais em toda fase da vida para 
desenvolver e manter um organismo sadio. Por isso, somente o ato de ingerir algum alimento qualquer, não proporcionará nutrientes necessário para um todo e na escassez de nutrientes, o organismo ficará debilitado e poderá desenvolver doenças (Maratoya et al. 2013).

Mas o acesso à alimentação infelizmente não está disponível a todas as pessoas, esse é um assunto que iria abordar várias vertentes, como questões biopsicossociais. A pobreza e a escassez alimentar em várias regiões do mundo, é um fator que impossibilita o acesso a esse recurso. Questões de renda familiar ou dos espaços em que as pessoas vivem, também afetam diretamente o acesso ao alimento (Maratoya et al. 2013).

\section{$1.1 \quad$ Objetivo}

Este artigo tem por objetivo revisar a literatura abordando questões relacionadas a diversas substâncias de diferentes alimentos que têm efeito benéfico à saúde; com isso poder entender melhor alguns pilares para longevidade relacionados à alimentação e também relacionar estes perfis com os alimentos consumidos por pessoas do interior de Minas Gerais, mostrando um pouco da culinária regional.

\section{Revisão da literatura}

\subsection{Cultura alimentar de povos mineiros}

Segundo Abdala, (2006) a culinária mineira possui fortes raízes caboclas e caipiras; as comidas típicas da região sofreram certas influências de povos indígenas, africanos e dos colonizadores europeus. A cozinha típica mineira ganhou forjamento entre os séculos XVIII e XIX quando em respectivas épocas era o auge na mineração e a ruralização da economia regional.

Lima, (2017) diz que a cultura alimentar no sistema familiar rural em uma cidade da zona da mata mineira, compõe-se de "comida forte" que causa bastante saciedade e ajuda a segurar a fome por bastante tempo; essas comidas 
típicas são baseadas nas carnes suínas e nas demais comidas feitas com a gordura do porco, sejam elas o feijão, arroz e alguns vegetais. Essas comidas fortes, se dão pelo fato de que os consumidores são trabalhadores rurais e fazem serviços de alta intensidade, então precisam de uma comida que os sustente por mais tempo. Peralta, et. al., mostra que a carne vermelha é uma fonte nutricional muito rica, dela pode-se ter o benefício de proteínas de alto valor biológico, contendo os aminoácidos essenciais para nosso organismo, vitaminas como B12, B9 e B6, ferro, zinco, selênio, entre outros.

FIGURA 1 - Carne de porco caipira

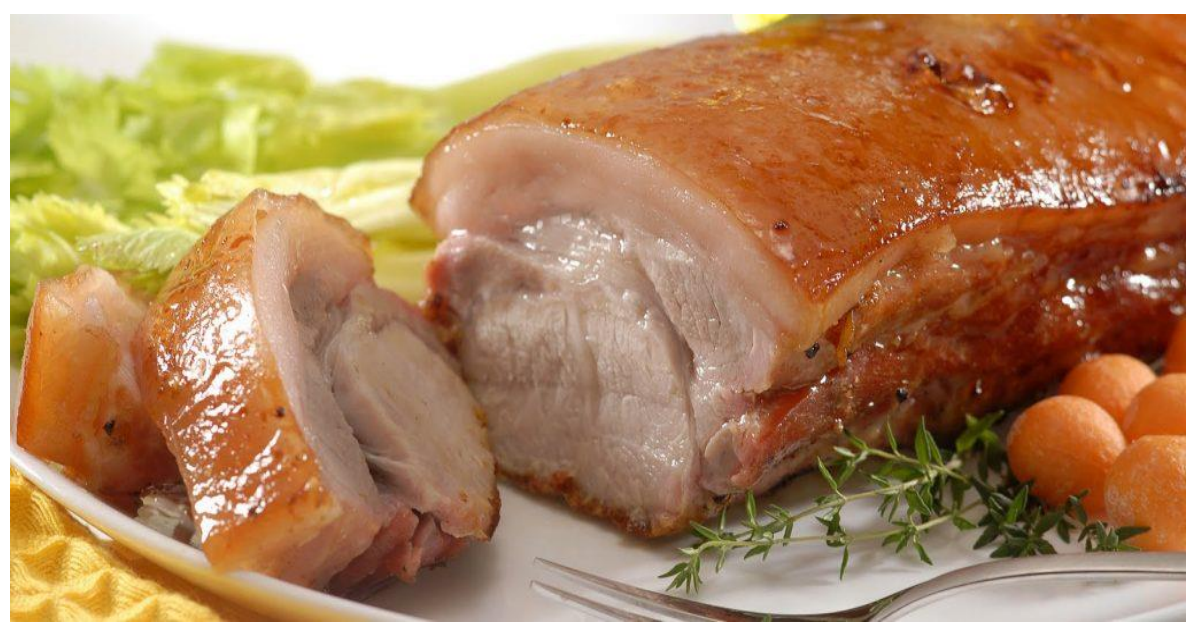

Fonte: raizesdiario.com.br (2019)

O consumo da mandioca e do milho teve grande influência indígena; desses ingredientes derivaram as canjicas, mingaus, papas, a farinha de mandioca que popularmente é conhecida no país inteiro, os bolos, doces e outras. A mandioca é uma ótima fonte de carboidrato de baixo índice glicêmico, possui algumas vitaminas e minerais fornecendo energia, saciedade e muito sabor à culinária. O milho contém muita fibra que é importantíssima para a saúde da microbiota, além de possuir vitaminas como vitamina $A$, algumas do complexo $B$, além de minerais como fósforo, potássio, entre outros. 
Revista Multidisciplinar do Nordeste Mineiro, v.1, 2021/01

ISSN 2178-6925

Figura 2 - Milho



Fonte: https://receitas.ig.com.br (2021)

Estes alimentos que comumente são cultivados pelos agricultores como uma cultura de subsistência, vêm fazendo parte do cardápio mineiro há muitos anos. Dizia Alves, (1990) a mandioca é produzida em solos de baixa fertilidade, contendo baixa precipitação de chuva anual de $600 \mathrm{~mm}$ no semiárido; isso mostra o quão este alimento é importante na vida dos mineiros, principalmente daqueles produtores rurais, que vivem da agricultura de subsistência, numa região de poucas chuvas, sem diversidade de alimentos disponíveis. 
Figura 3 - Mandioca cozida

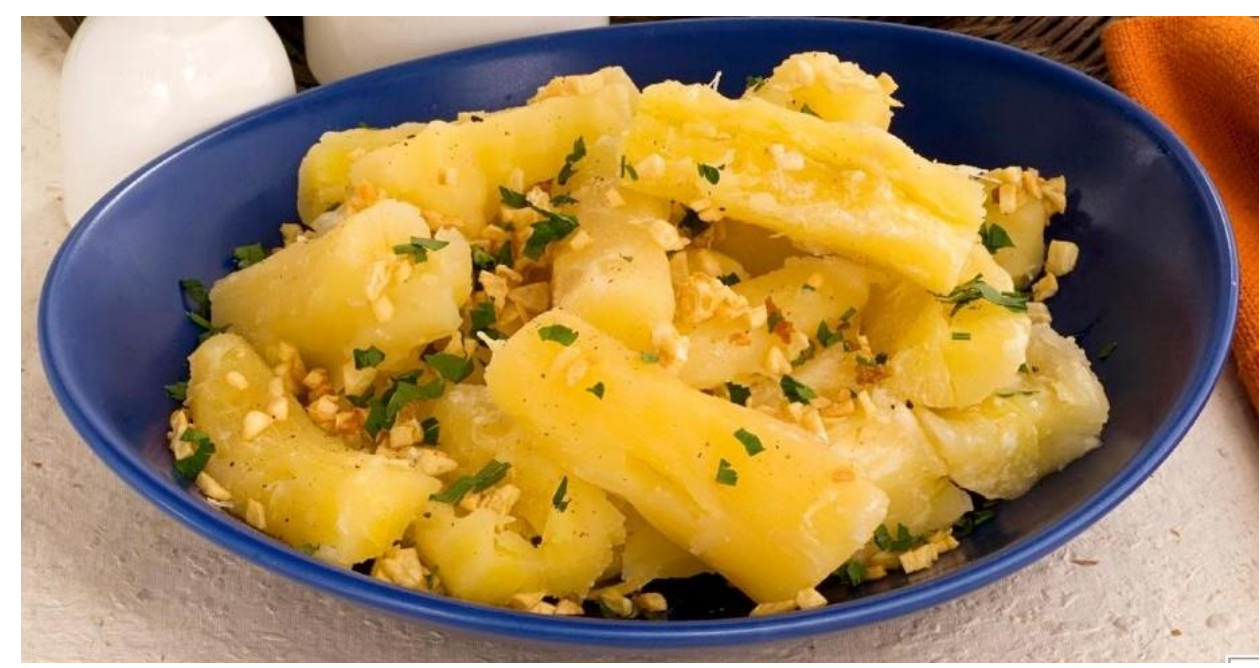

Fonte: guiadacozinha.com.br (2021)

O consumo de ovos de galinha, segundo Abdala, (2006) veio dos portugueses e proporcionou um vasto rendimento culinário. $O$ ovo é um alimento que popularmente sempre esteve à mesa do mineiro, muito usado na alimentação cotidiana também sendo uma forma de subsistência regional. Este alimento é uma ótima fonte de proteína animal, Novello et.al., (2006) diz que é um alimento completo, de alta qualidade e preço acessível, rico em proteínas, vitaminas do complexo $B, A, E$ e $K$, possui minerais como fósforo selênio e zinco, além de carotenóides como luteína e zeaxantina. 
Figura 4 - Ovos caipira

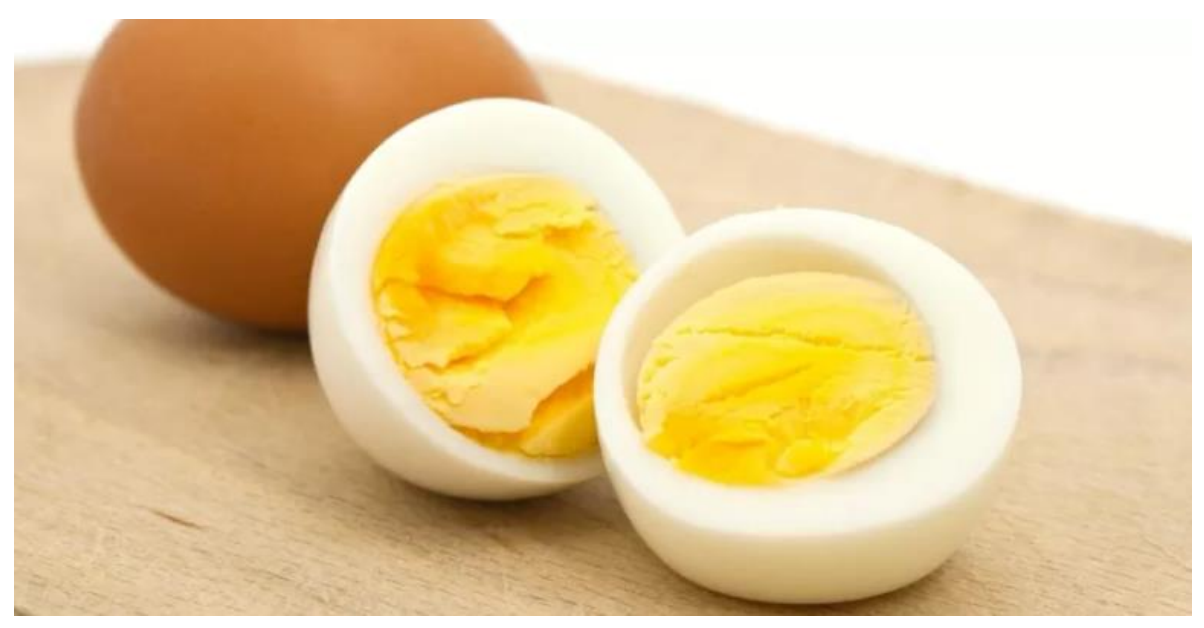

Fonte : uol.com.br (2021)

O maxixe e o quiabo fazem parte da alimentação da população brasileira, especialmente no nordeste, sudeste e norte do País, onde se adaptaram muito bem ao clima tropical e subtropical. Estes alimentos são utilizados tanto para subsistência, quanto para fins comerciais. Em regiões de Minas Gerais, especialmente no nordeste do Estado, têm fortes hábitos de onsumo destes alimentos; esses vem há gerações à mesa do mineiro. O maxixe é rico em minerais que se destacam como o zinco, que ajuda a evitar problemas na próstata, na diminuição dos depósitos de colesterol e na cicatrização. Ele também tem poder de evitar hemorroidas, possui ação emoliente, catártica, antihelmíntica, além de possuir estudos que demonstram ter compostos bioativos que combatem radicais livres (SOUSA, LIMA e LIMA, 2015). 
Revista Multidisciplinar do Nordeste Mineiro, v.1, 2021/01

ISSN 2178-6925

Figura 5 - Maxixe

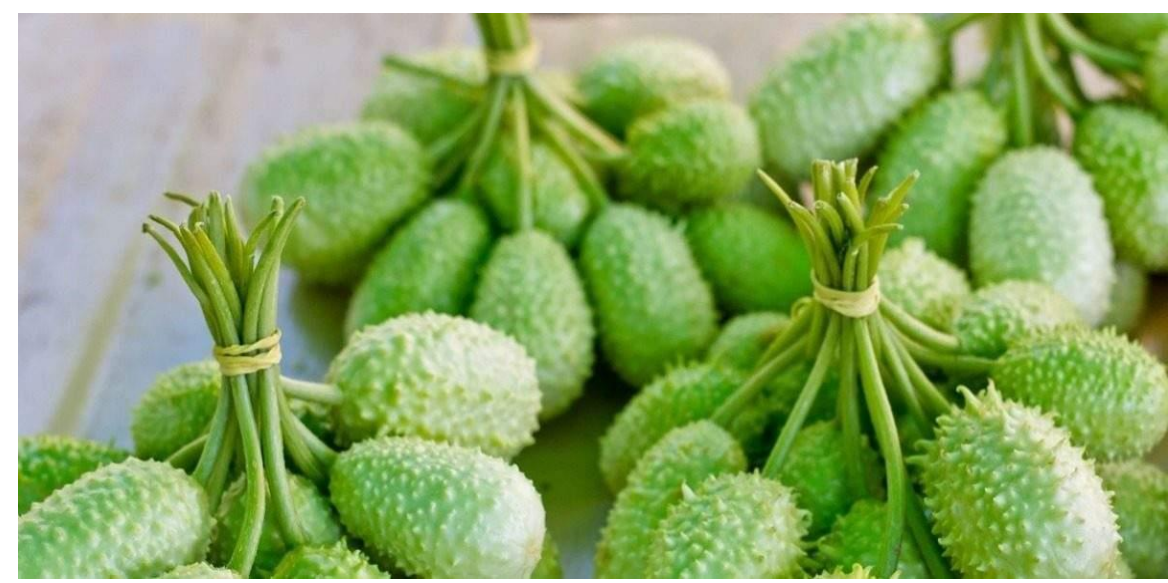

Fonte : https://cuidai.com.br (2020)

O quiabo é um alimento que possui baixo teor de carboidratos, oferece ao organismo nutrientes como fibras, proteínas e vitaminas $\mathrm{C}$. Ele também é rico em pro vitamina A, B1, e minerais como cálcio e ferro. Possui propriedades medicinais como anti-helmíntico, antiparasitário, indicado no tratamento de verminose, diarreia, inflamações, além de sua quantidade calórica ser baixa, fazendo com que possa haver um consumo de bastante volume e poucas calorias (SOUSA, LIMA e LIMA, 2015).

Figura 6 - Quiabo 


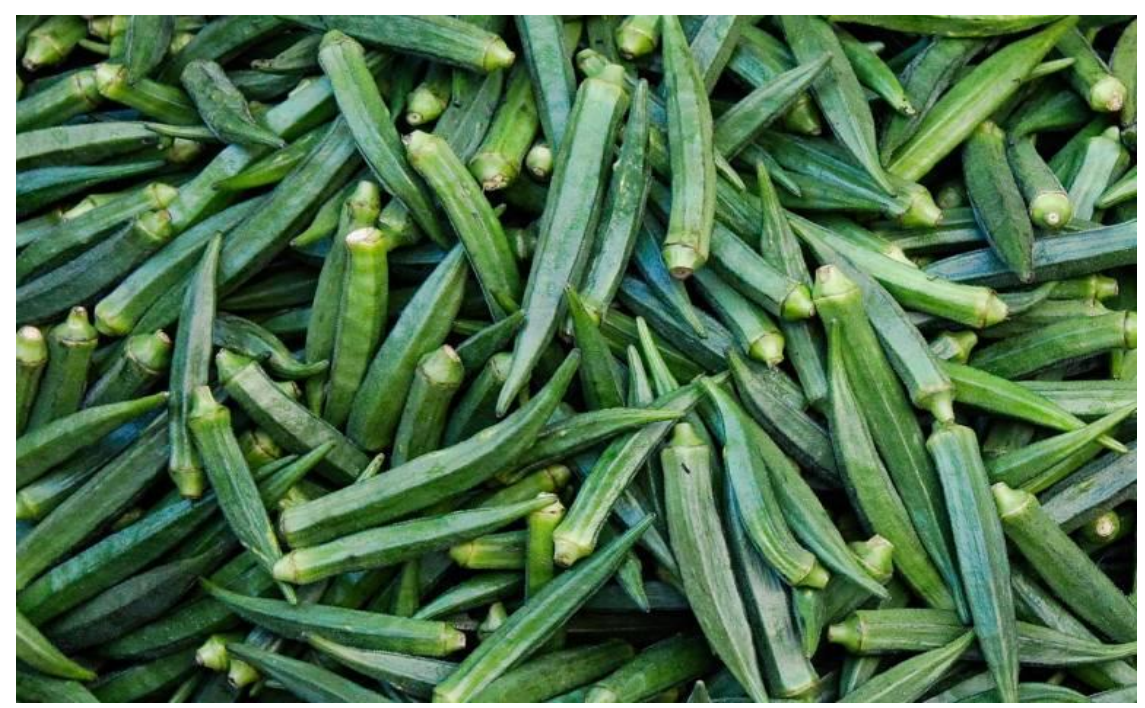

Fonte : https://jornalcinco.com.br (2021)

Não se pode deixar de falar do queijo, que é um alimento tradicionalmente popular na culinária dos povos de Minas Gerais. Lima, (2017) diz que o queijo foi importado de outras regiões do país até o final do século XVIII, e século XIX os queijos apresentavam-se as mesas como acompanhantes de sobremesas, doces, geleias etc. Também já se incrementaram na cultura do café da manhã e lanches, sendo acompanhado de café, farinhas e angu com leite. O crescimento e popularização da produção de queijo, veio em crescente demanda devido ao crescimento da pecuária, havendo com isso grande produção de leite, assim utilizando toda matéria prima para sua produção. No geral, o consumo de laticínios como o queijo e o leite, faz parte a muito tempo da alimentação dos mineiros, estes alimentos, possuem importantes nutrientes para saúde humana, como proteínas de alto valor biológico que estão associadas à manutenção da massa muscular corporal, vitaminas e minerais como cálcio e vitaminas $D$ e também bebidas fermentadas como iogurtes que possuem probióticos, ótimos para saúde da microbiota intestinal.

Figura 7 - Queijo 


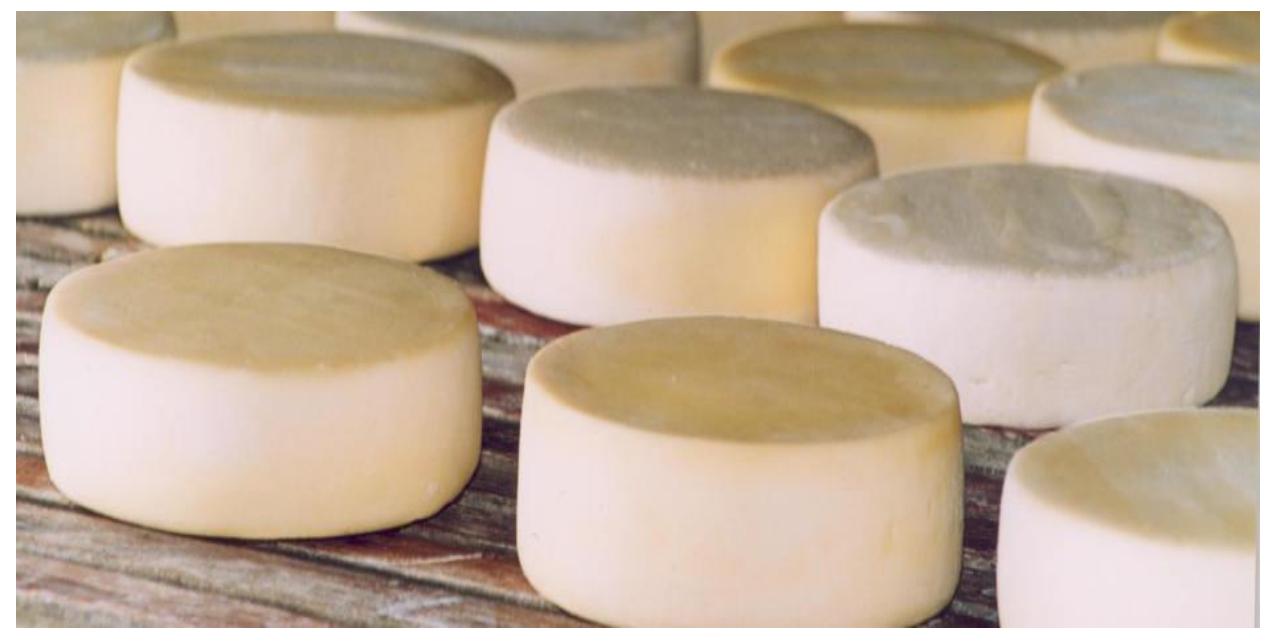

Fonte : agenciaminas.mg.gov.br (2020)

A carne de aves em especial a galinha, mais popularmente conhecida pelos mineiros do interior como galinha caipira, é utilizada há muitos anos como um alimento essencial na vida destas pessoas. A galinha caipira é comumente encontrada no comércio regional do Estado, mas em especial tem um forte destaque por ser criada em quintais, cercados e criadouros, pelos próprios consumidores; por ser de fácil criação e também por que representa um forte traçado cultural. A carne de frango é considerada um alimento saudável, rico em proteínas de alto valor biológico e é muito importante seu consumo em todas as idades; também possui ferro e vitaminas do complexo B como B2 e B12. Sua quantidade de gorduras é muito baixa; o peito, por exemplo, possui apenas $2 \%$ destas; a pele possui mais quantidade, mas pra quem tem contra indicações ao consumo destas gorduras, pode consumir sem a pele, assim terá uma ótima qualidade de carne magra (Venturine, Sarccinelli e Slilva, 2007).

Figura 8 - Galinha caipira 


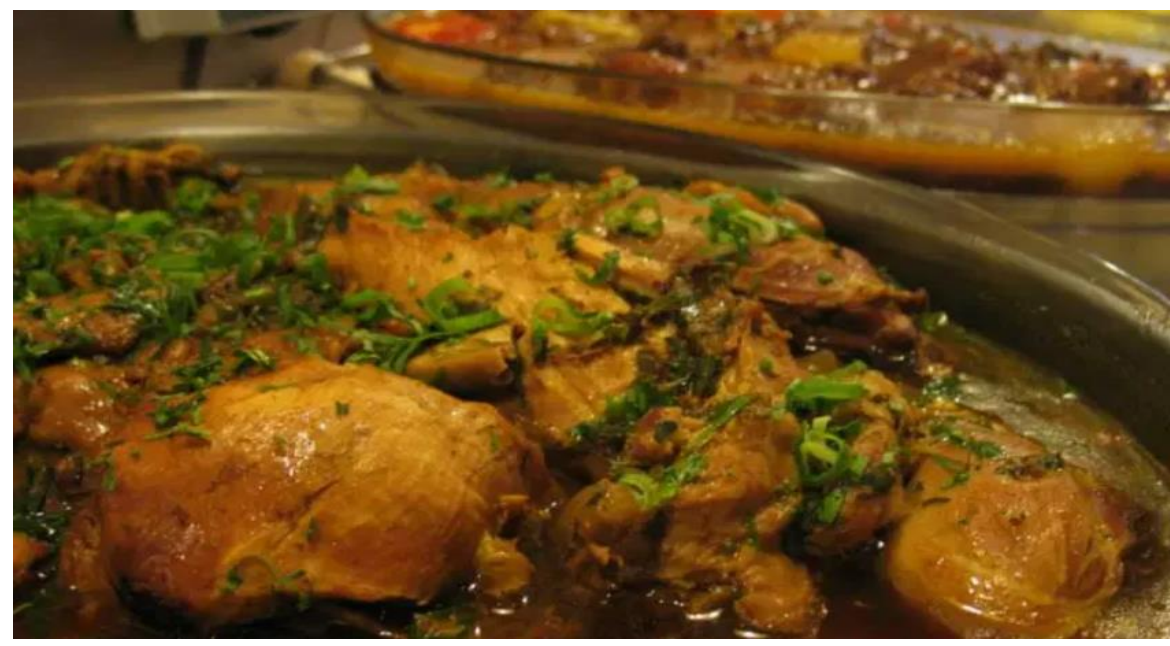

Fonte: https://veja.abril.com.br (2017)

O arroz e o feijão são dois típicos alimentos populares brasileiros e não podia deixar de associá-los ao estudo, pois basicamente a principal comida do brasileiro e do mineiro sempre foi o bom e velho arroz com feijão. Ambos são cultivados por produtores rurais que os tem como fonte de subsistência e também com fins comerciais. O mineiro faz uso destes alimentos como sua fonte diária de almoço e jantar; esses fornecem nutrientes essenciais para uma boa e saudável alimentação.

O arroz representa um dos cereais básicos da dieta humana; é constituído essencialmente de amido e é fonte de proteína. Sua camada periférica é rica em fibras e vitaminas do complexo $\mathrm{B}$, o germe e o embrião possuem proteínas e lipídios. O arroz é uma ótima fonte de carboidrato, representando pelo menos $20 \%$ da ingestão mundial de energia, como na Ásia, que perfaz boa quantidade do aporte energético e proteico dos habitantes. $O$ arroz possui micronutrientes, dentre eles a Tiamina, Riboflavina, Niacina, ferro e zinco (Naves, 2007).

O feijão no Brasil é considerado um dos maiores alimentos comercializados e também demanda um consumo muito grande entre os povos, principalmente por que fornece boas qualidades nutricionais; por exemplo, 0 feijão é uma ótima fonte de ferro, nutriente do qual grande parte da população sofre deficiência desse mineral; também é rico em fibras, possui proteínas e uma carga calórica baixa (Mechi, Caniatti-Brazaca e Arthur, 2005). 
Revista Multidisciplinar do Nordeste Mineiro, v.1, 2021/01

ISSN 2178-6925

O feijão proporciona energia para uma vida saudável, como proteínas ricas em lisina, vitaminas do complexo $B$, sais minerais como ferro, potássio e fósforo, além de fibras que ajudam a controlar os níveis de colesterol e glicose sanguíneos. A grande quantidade de lisina presente no feijão juntamente com outros aminoácidos do arroz, fazem destes alimentos uma combinação saborosa e nutritiva (Chaves e Bassinello, 2014).

Figura 9 - Arroz com feijão

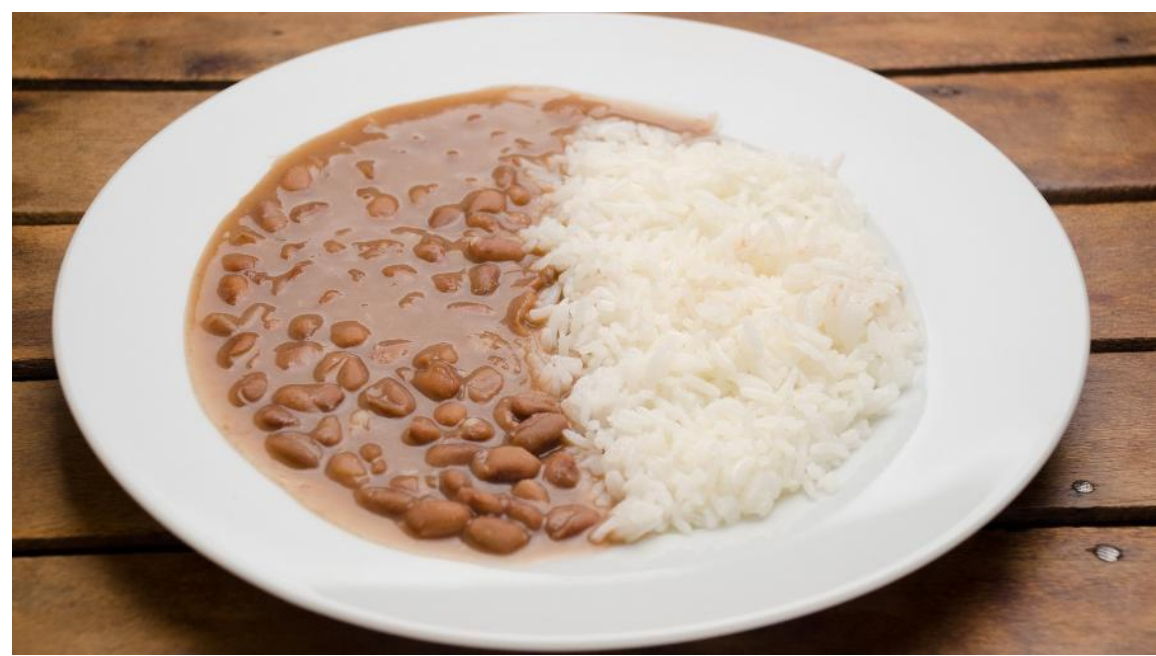

Fonte : https://www.ibrafe.org/ (2019)

O pequi é um alimento encontrado em regiões típicas do cerrado brasileiro, mas pode ser encontrado em diversos estados do país. É fortemente 
consumido na região Nordeste do qual tem grandes características culturais. No Nordeste de Minas Gerais é muito comum encontrar um grande comércio deste alimento, ele é bem característico da cultura mineira regional e é usado de diversas formas na culinária, como cozido no arroz, feijão, carnes, frangos, baião de dois, entre outros pratos. O pequi fornece parte dos aportes energéticos e nutricionais especialmente para famílias carentes, no período da safra. Seu óleo é extraído e utilizado na culinária, na indústria cosmética, na produção de sabão, em remédios para combate à bronquite e gripe. Sua polpa é rica em pro vitamina A, possui vitamina $C$, em torno de $72,27 \mathrm{mg} / 100 \mathrm{~g}$, valor superior ao encontrado em algumas frutas cítricas, como laranja e limão. Estudos demonstraram que o pequi possui carotenóides, que tem ação antioxidante, sendo considerado um alimento funcional; ele também possui tiamina, riboflavina, niacina, e caroteno, entre outros (Oliveira et. al., 2008).

Figura 10 - Pequi



Fonte: https://ecoa.org.br (2015) 
Diante dos temas expostos, segue adiante uma revisão de literatura sobre nutrientes essenciais para o bom desempenho do organismo.

\subsection{Alimentos funcionais}

Vidal et. al., (2012) diz que, os alimentos funcionais são aqueles que vão além da ingestão de calorias e simples nutrientes para saciar a fome, eles possuem substâncias capazes de promover efeitos benéficos ao organismo, envolvendo funções fisiológica e metabólica por meio do desempenho de algum nutriente. Estes alimentos possuem substâncias que contribuem para uma ou mais funções orgânicas, que além de estar cumprindo a nutrição básica como alimento, diminuem o risco de desenvolver doenças, auxiliando no estado de saúde e bem estar ( Carvalho, et. al. 2006) .

Segundo Oliveira et. al., (2002) os alimentos funcionais atuam na prevenção de doenças, ao invés de procurar atingir somente a cura. Estes alimentos a longo prazo podem ser benéficos ao organismo, promovendo longevidade. Dentre estes alimentos, ganham maior fundamento os que possuem fibras, minerais, óleos de peixe, vitaminas, probióticos e esteróis de plantas (Thamer e Penna, 2006).

Figura 11- alimentos funcionais

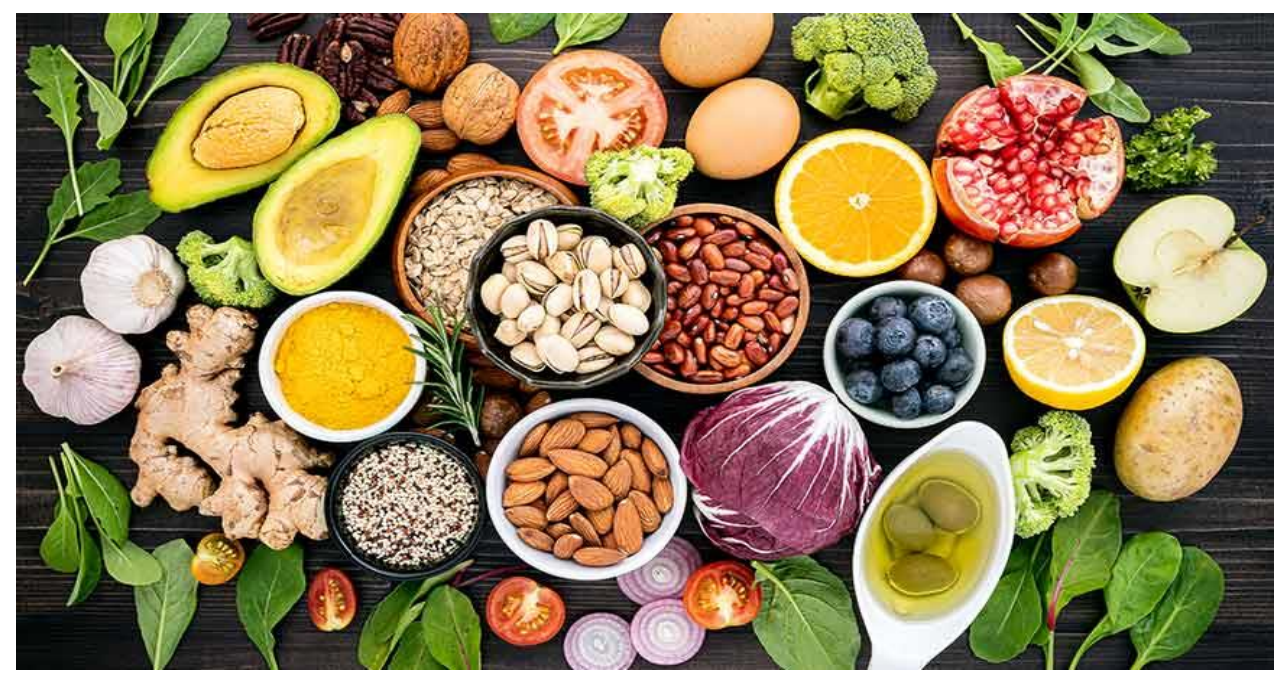


Fonte: https://www.revistaabm.com.br (2020)

\subsection{Hortaliças, vegetais e sua funcionalidade}

O consumo de hortaliças segundo Carvalho (2006) está diretamente associado a prevenção do câncer. Foram feitos vários levantamentos epidemiológicos que resultaram numa associação entre uma dieta rica em hortaliças e valor efetivo na prevenção do desenvolvimento do câncer. Para reduzir entre $60 \%$ e $70 \%$ o risco de desenvolver esta doença, recomenda-se segundo o American Institute of Cancer Research, (2006) o consumo de uma dieta rica em diversidade de frutas e vegetais preferencialmente cruas e com cascas para se obter melhor os nutrientes destes alimentos. Uma dieta com uma boa quantidade e variedade de hortaliças irá proporcionar uma maior diversidade de nutrientes essenciais para o organismo. Carper, (1995) demonstra que a maior parte das hortaliças contém bioflavonóides que combatem radicais livres e hormônios que desenvolvem câncer; as de cores amarelo-alaranjadas, por conterem beta-caroteno, previnem mutações celulares e oxidação do colesterol LDL; as verde escuras reduzem o risco de catarata e degeneração macular senil por conterem luteína e zeaxantina; o tomate e a melancia, por possuírem o licopeno, seu consumo pode reduzir em grandes chances o risco de desenvolver câncer de próstata.

Figura 12 - Hortaliças e vegetais 




Fonte: segredosdomundo.r7.com (2019)

\subsection{O benefício das fibras}

As fibras alimentares estão presentes nos vegetais e elas são de grande importância para o bom funcionamento do intestino e funções do organismo, sendo bem resistentes a digestão humana, sendo assim, sua fermentação ocorre boa parte no intestino grosso. Elas são divididas de uma forma simplificada em: fibras solúveis que são facilmente fermentadas no cólon, aumentando o tempo do trânsito intestinal, exemplo disso, boa parte da pectina, goma e certas hemiceluloses. E as insolúveis, sendo celulose, lignina e grande parte das hemiceluloses que tem como ação aumentar o volume do bolo fecal e retardar o trânsito intestinal, por exemplo o farelo de trigo. Também são os processos físico-químico que acontecem durante a digestão, que dão as fibras sua característica funcional (Mira; Graf; Cândido, 2009).

Figura 13 - fibras 




Fonte: https://www.hospitalsiriolibanes.org.br (2014)

As fibras tem destaque na função intestinal; uma dieta rica em fibras, irá proporcionar uma boa saúde do intestino melhorando o processo de evacuação e mantendo a microbiota saudável e para que para isso ocorra deverá haver a ingestão de fibras diária. Recomenda-se a ingestão de pelo menos $25 \mathrm{~g}$ a $30 \mathrm{~g}$ por dia para uma pessoa adulta, associada a um consumo de água diário eficiente (Catalani et. al., 2003).

As fibras denominadas beta-glucanas estão presentes na aveia, cevada e psyllium, são responsáveis pela diminuição do colesterol e ajuda a evitar possíveis doenças do coração, recebendo reconhecimento e indicação da Food and Drug Administration que declarou como alimento benéfico à saúde. Segundo Chandalia, (2000) estudos têm demonstrado que a ingestão das fibras solúveis age retardando o esvaziamento gástrico e diminuindo a absorção de glicose, isto beneficia a glicemia pós prandial de portadores de diabetes. Também estudos têm demonstrado uma relação inversamente proporcional em homens que ingerem fibras diariamente e diabetes. As fibras estão presentes em grande quantidade nas hortaliças, nas frutas, de preferência com cascas, nas leguminosas e nos vegetais em geral. (Mira; Graf; Cândido, 2009).

Figura 14 - cereais 


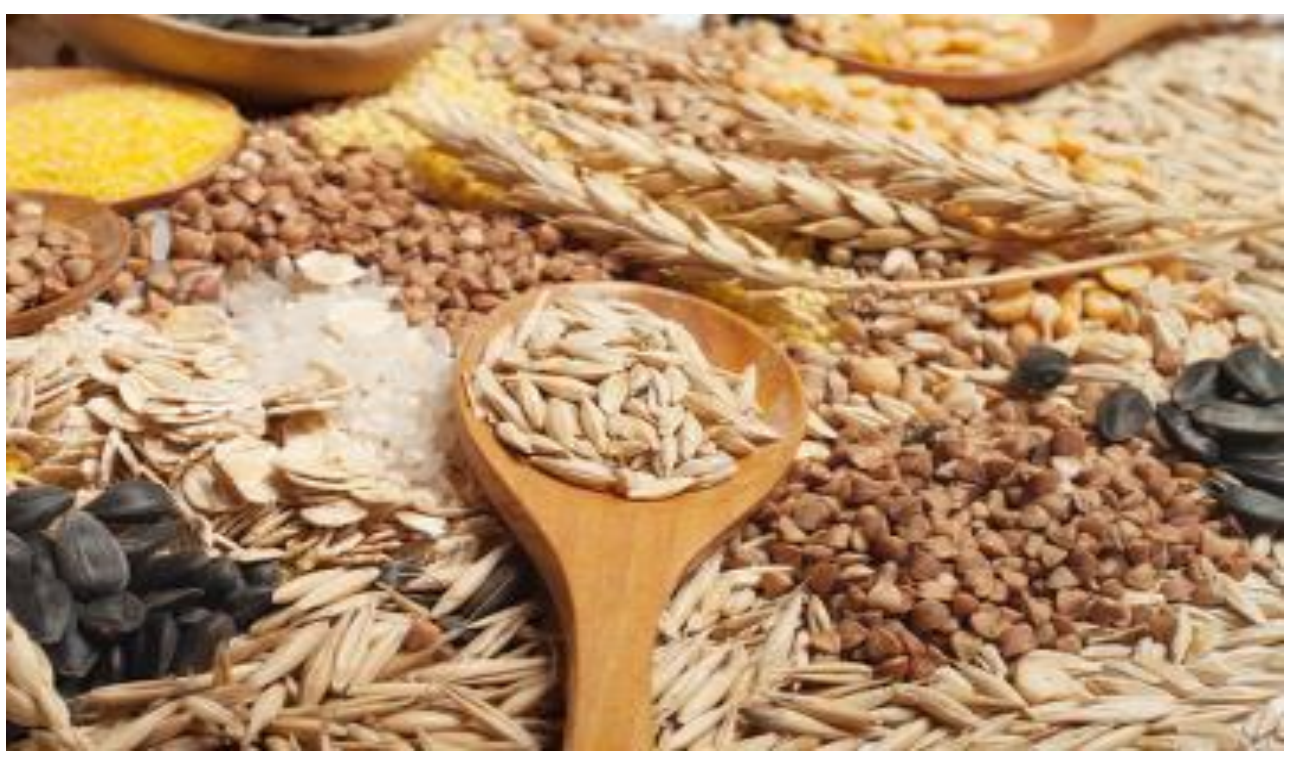

Fonte: https://www.diabetes.org.br/ (2017)

\subsection{Antioxidantes para saúde}

É necessário haver um equilíbrio entre a produção de radicais livres e as defesas antioxidantes para uma boa manutenção e funcionamento do organismo. Quando há muita produção destes radicais, se dá o nome de estresse oxidativo. É nessa condição que os radicais livres podem oxidar e também danificar lipídios celulares, DNA e proteínas, isso faz com que altere sua função normal e poderá desencadear doenças cancerígenas, mutações, complicações no sistema imunológico, entre outras. Os antioxidantes têm um papel fundamental nesta perspectiva, sendo que uma dieta rica dessas substâncias, irá auxiliar no sistema protetor endógeno do organismo, que é um grande agente defensor destes radicais (Ferreira e Abreu, 2007).

Segundo Biachi e Antunes, (1999) os antioxidantes irá impedir a formação dos radicais pelas inibições de reações em cadeia com o ferro e o cobre, eles são capazes de interceptar os radicais livres produzidos pelo metabolismo e proteger as células do organismo, evitando lesão e perda de integridade celular. As vitaminas $A, C$ e $E$, os carotenóides e flavonóides são importantes na 
Revista Multidisciplinar do Nordeste Mineiro, v.1, 2021/01

ISSN 2178-6925

interceptação dos radicais livres, estes e outros são capazes de reparar lesões causadas por esses agentes maléficos.

Figura 15- alimentos antioxidantes



Fonte: https://www.indice.eu (2020)

Os carotenóides têm ação pró-vitamínica $A$, são encontrados em alimentos de cores vermelho alaranjados e estudos demonstram que seu consumo possivelmente trará benefícios à saúde como o aprimoramento do sistema imunológico, possível prevenção de doenças degenerativas como câncer, catarata e doenças do coração. O licopeno que é um carotenóide presente no tomate e seus derivados, além da goiaba e melancia, possui fundamentos que sua funcionalidade atua na prevenção do câncer de próstata por atuarem no combate aos radicais livres e também atuam na prevenção da oxidação do LDL reduzindo o risco de desenvolvimento de arteriosclerose e doenças coronárias (Valduga et. al., 2009). 
Figura 16- Alimentos fonte de carotenóides

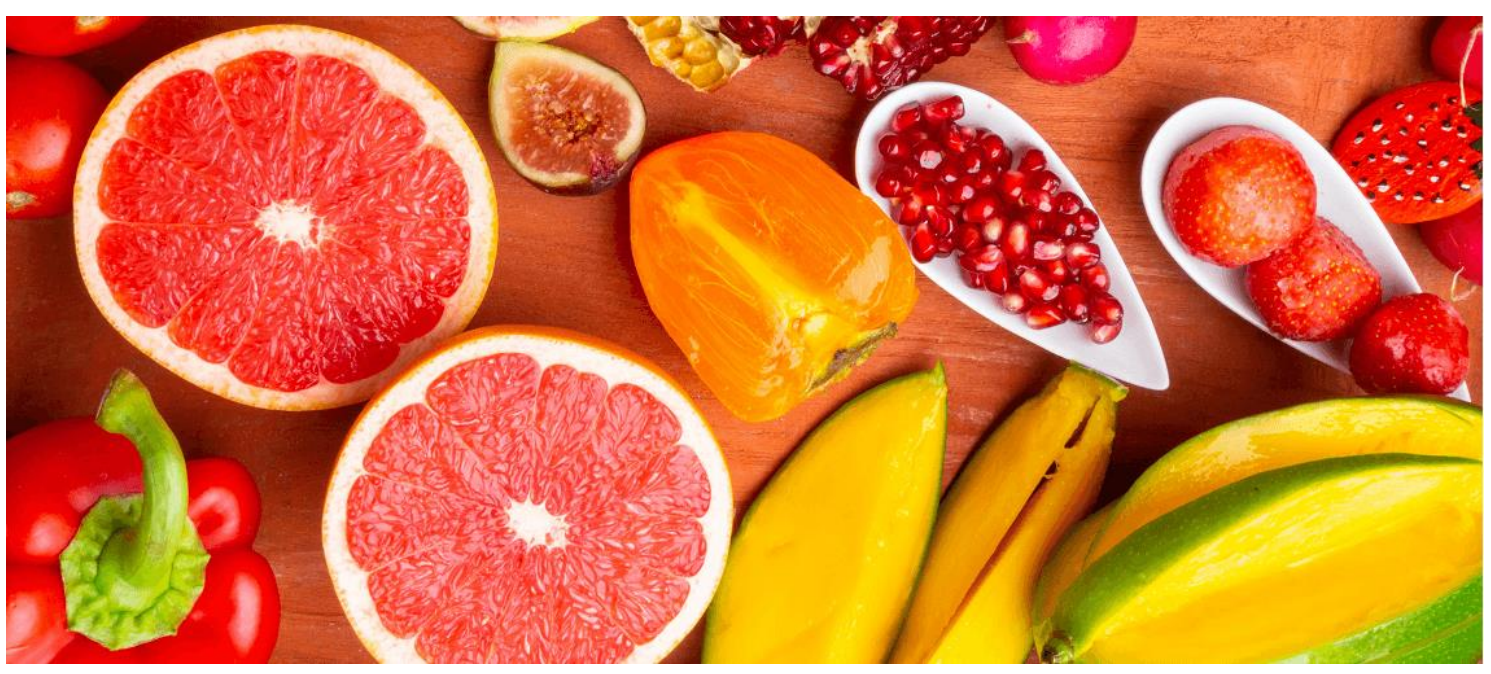

Fontes: https://nutritotal.com.br/ (2020)

A vitamina $C$ dos alimentos é encontrada na maior parte em frutas e hortaliças e é um antioxidante hidrossolúvel de grande importância para o organismo. Ela é responsável pela diminuição de radicais livres de diferentes formas, como o radical hidroxil e superóxido, além disso estudos mostraram que o ácido ascórbico tem potencial de prevenir mutações no DNA humano. Alimentos como acerola, laranja, limão, goiaba, manga, entre outros, são fontes de vitamina $\mathrm{C}$ e seu consumo diário é benéfico ao organismo (Oliveira et. al., 2011).

Os fitoesteróis ganhou uma provação científica que reduziam os níveis séricos de colesterol, então estudos recentes também demonstraram que essas substâncias podem reduzir as chances de desenvolver doenças relacionadas ao envelhecimento, como câncer e principalmente doenças do coração, que é a área a qual estas substâncias ganharam maior força. O Programa Americano de Educação ao Colesterol, indica o consumo de $2 \mathrm{~g}$ ao dia, juntamente a outros hábitos saudáveis para que o consumo de alimento contendo estas substâncias, podem reduzir os níveis de LDL colesterol. Alimentos como grãos de soja, sementes vegetais como de gergelim, girassol, amendoim, entre outros, são principais fontes naturais deste nutriente (Breda, 2010). 
Figura 17 - Alimentos contendo fitoesteróis

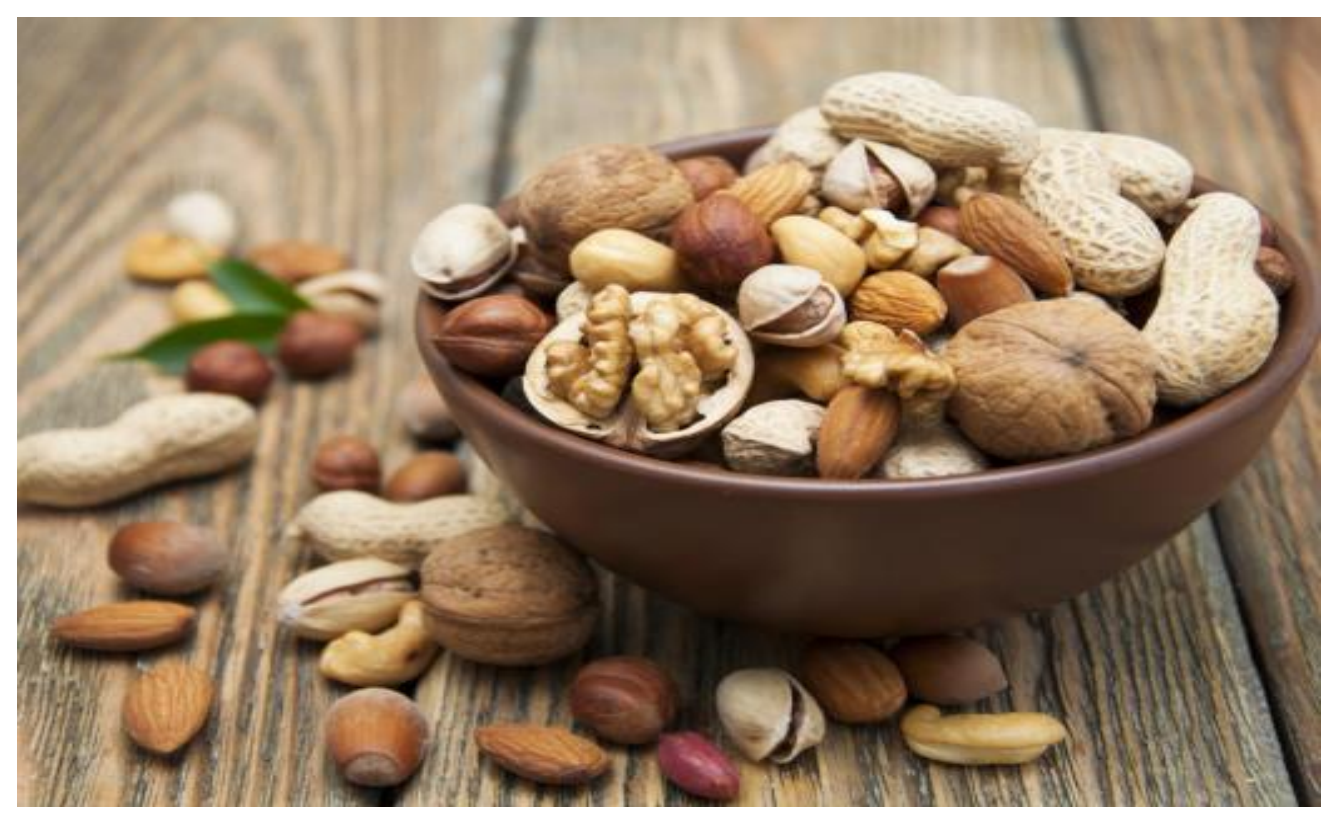

Fonte: portalmedic.com.br (2016)

Flavonóides são substâncias encontradas em alimentos de origem vegetal como frutas, vegetais, chás, vinho, chocolate amargo etc. Eles possuem compostos bioativos que têm propriedades anti-inflamatória e são muito usados na farmacologia graças às suas propriedades. Por meio de estudos já se provaram a potência de sua capacidade benéfica em alguns aspectos biológicos, sua capacidade antioxidativa é a atividade que mais chama atenção dos estudiosos. Além disso, essas substâncias possuem capacidade de atividade antialérgica, anti-hepatóxica, possuem ação inibitória do crescimento de tumores, e também ações antivirais e antimicrobianas (Coutinho, Muzitano e Costa, 2009). 
Figura 18 - Alimentos fonte de flavonóides



Fonte: https://eagorainst.wordpress.com (2013)

\subsection{Probióticos e sua eficácia}

Os microrganismos probióticos, segundo Oliveira et. al., (2002) são determinadas bactérias lácticas que agem em função benéfica ao consumidor, que no caso seria o hospedeiro. Essas bactérias, agem melhorando o balanço microbiano intestinal, elas devem colonizar o intestino, mesmo que por certo tempo e sobreviver às condições do estômago. As bactérias ácido-lácticas, as não ácido-lácticas e leveduras são usadas como probióticos.

Coppola e Gil-Turnes, (2004) mostram que os probióticos são usados no ramo da medicina como substâncias capazes de prevenir e tratar doenças, dentre estas, destacam-se o tratamento em distúrbios do trato gastrointestinal, estas também atuam como imunomoduladores, atuam no regulamento da microbiota intestinal e na inibição da carcinogênese. Oliveira et. al., (2002) também diz que a fermentação destas substâncias, podem causar uma melhora na digestibilidade dos alimentos e produzir vitaminas e cofatores em alimentos.

Apesar de não ter estudos que demonstram como isso ocorre, os probióticos tem efeito imunoestimulante nos animais e no homem. Este efeito pode estar ligado ao fato dos probióticos interagirem com a placa de Peyer e as 
células epiteliais intestinais, estimulando as células produtoras de $\lg \mathrm{A}$ e a migração de células $T$ intestinais. A Introdução de certos lactobacilos em camundongos gnotobióticos, teve como resposta a proteção contra patógenos intestinais pela indução do aumento da capacidade fagocítica dos macrófagos peritoniais e das atividades envolvidas na fagocitose (COPPOLA e GILTURNES, 2004).

No Brasil calcula-se que o consumo de leites fermentados contendo probióticos como em torno de 120 mil toneladas ao ano segundo a (Food Ingredients, 2000). Na maioria dos comércios, o iogurte que é o mais popular em termos de bebida fermentada e está disponível ao consumo humano, bebidas fermentadas e outros produtos à base do mesmo, também são encontrados com facilidade nos mercados (OLIVEIRA et. al., 2002).

Figura 19 - Probióticos

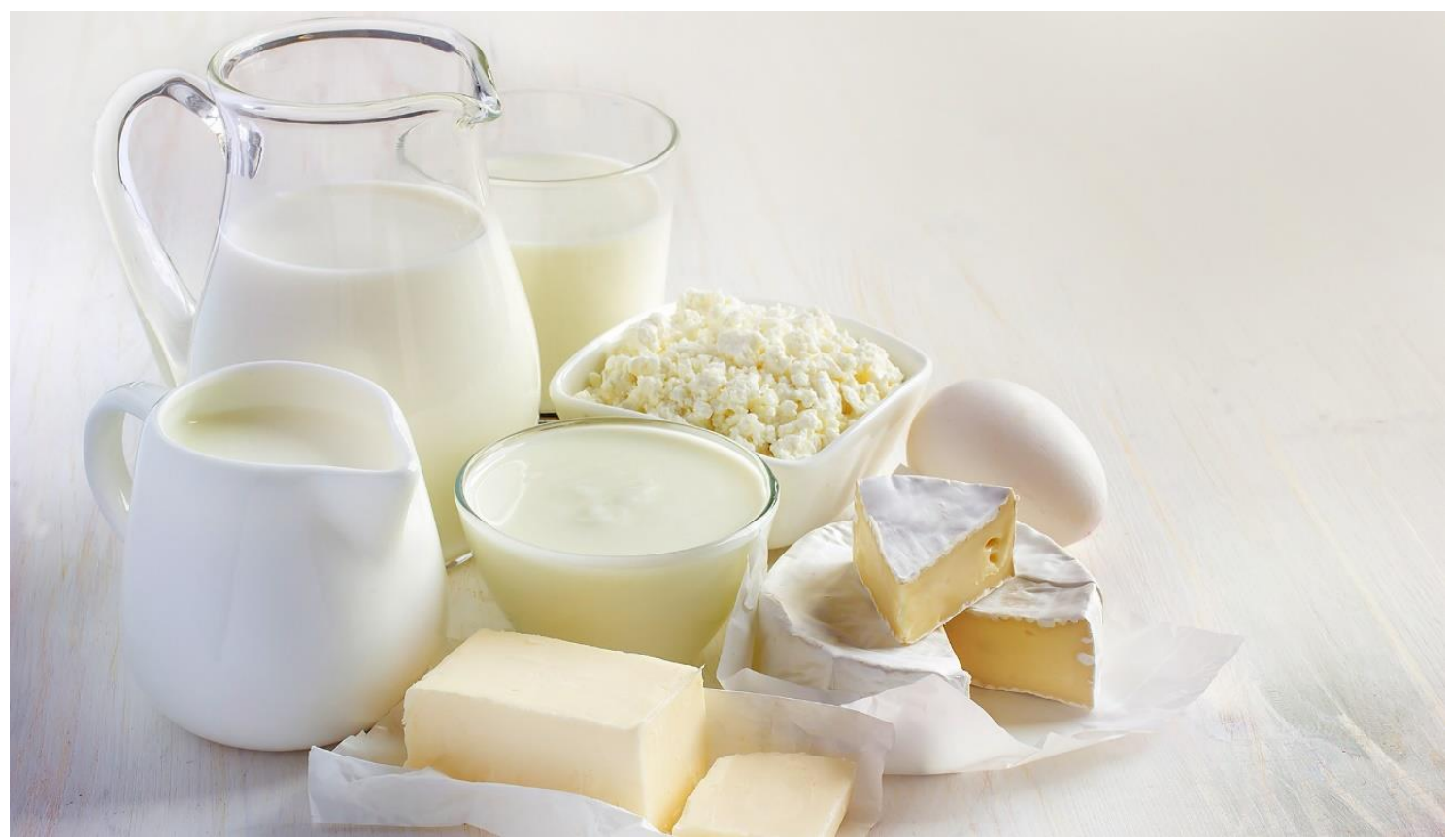

Fonte: http://blog.cicloorganico.com.br/ (2019) 
Os ácidos graxos ômega 3 e ômega 6, fazem parte dos ácidos graxos poliinsaturados, eles desempenham um papel importante nas estruturas das membranas celulares e processos metabólicos, também no desenvolvimento do cérebro e retina, e nos seres humanos os ácidos linoléico e alfa-linolênico, desencadeiam um processo importante nas funções cerebrais, na transmissão de impulsos nervosos, na transferência do oxigênio para o plasma sanguíneo, da síntese da hemoglobina e divisão célular (Martin, et. al., 2006).

Os ácidos linoléico e alfa-linolênico estão disponíveis em alimentos de origem animal e vegetal. Nos vegetais, encontram-se em maior quantidade presente nas hortaliças de coloração verde escura, também se encontra em algumas espécies de leguminosas e cereais, mas a maior parte dos ácidos graxos poliinsaturados são encontrados em alimentos vegetais de ambiente aquático marinho. As hortaliças apresentam baixa quantidade de ácido linoléico e alfa-linolênico, devido a sua baixa concentração lipídica, mas o consumo destes alimentos pode ser essencial para obtenção deste nutriente. O agrião, couve, alface, brócolis, espinafre, aveia, arroz, feijão, soja e ervilha, contêm certa quantidade desses ácidos; especialmente para pessoas vegetarianas, o consumo destes alimentos pode ajudar na obtenção do nutriente. Os óleos vegetais, o de canola, soja e linhaça, apresentam quantidade significativa de ácido alfa-linolênico. Nos alimentos de origem animal, dependerá da dieta do animal para definir a quantidade desses ácidos. Os peixes apresentam grandes quantidades destes ácidos, em especial, os de origem marinha como o salmão e a sardinha apresentam maiores quantidades do que outros peixes, pois sua alimentação baseada em fitoplâncton permite a obtenção deste nutriente (Martin, et. al., 2006).

Figura 20 - Fontes de ácidos graxos poliinsaturados 
Revista Multidisciplinar do Nordeste Mineiro, v.1, 2021/01

ISSN 2178-6925

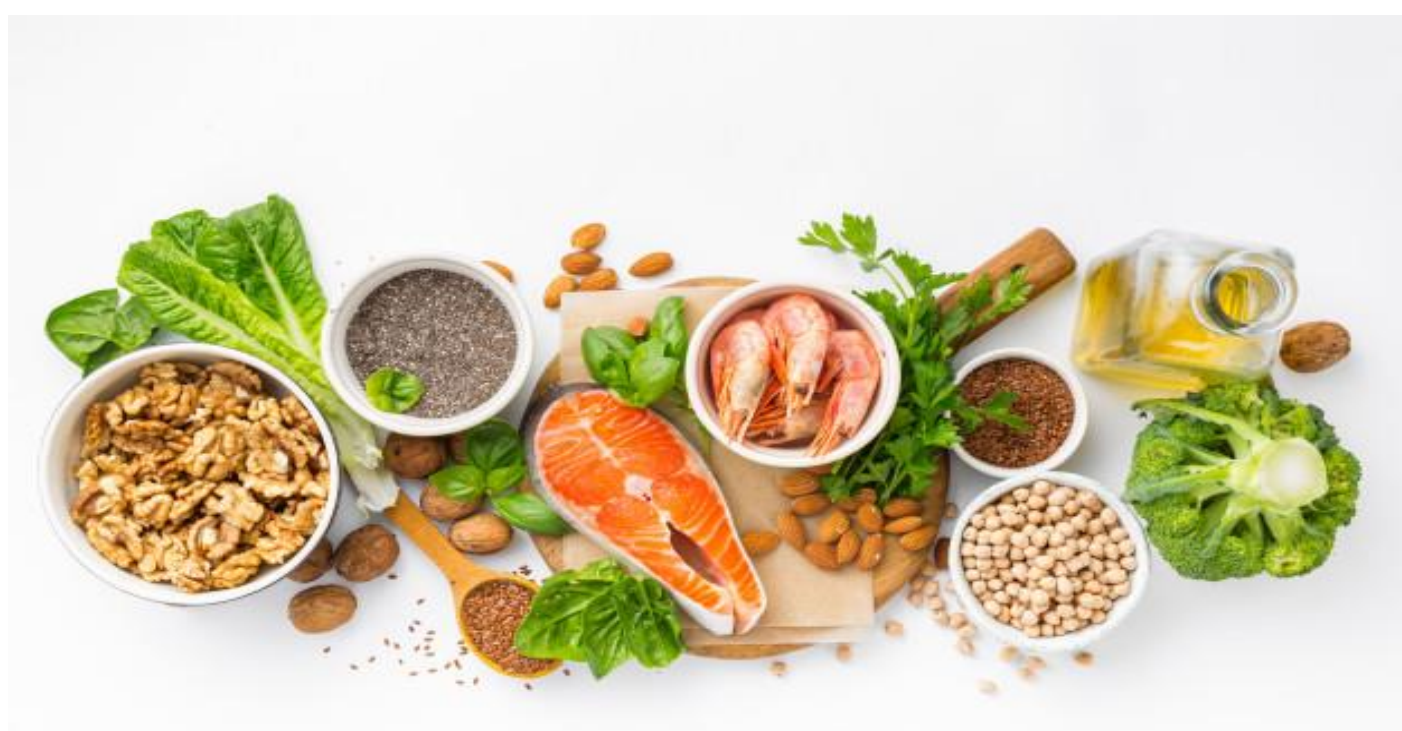

Fonte: https://br.freepik.com (2020) 


\section{Considerações finais}

Este estudo demonstrou por meio de uma análise literária os nutrientes essenciais para um bom desempenho do organismo humano e como pode-se obter tais nutrientes consumindo alimentos que na maioria dos casos são de fácil acesso, pois se trata de alimentos naturais, cultivados e comercializados pelos mais simples produtores e que se encontram disponíveis nos comércios. Este trabalho demonstrou que o consumo de alimentos in natura, associados a bons hábitos, resulta-se em qualidade de vida. Foi demonstrado que uma dieta rica em vegetais, frutas, fibras, probióticos, alimentos funcionais que possuem antioxidantes, qualidade nas escolhas de carboidratos, proteínas e gorduras, estão associados à prevenção de doenças, saúde do organismo e consequentemente longevidade. Também foi relacionado o perfil alimentar da população de Minas Gerais, em especial, do interior e como os alimentos consumidos por ela contêm nutrientes essenciais para um bom desempenho do organismo, proporcionando qualidade de vida à essa população. A alimentação das pessoas do interior mineiro é mais direcionada a alimentos naturais, derivados da agricultura e pecuária, e muitas vezes essas dependem propriamente do consumo desses para a própria subsistência. Fato é que, estes são bons alimentos e que oferecem nutrientes essenciais para saúde dessas pessoas. 
Revista Multidisciplinar do Nordeste Mineiro, v.1, 2021/01

ISSN 2178-6925

\section{REFERÊNCIAS}

ALVES, A. A. C. fisiologia da mandioca. Embrapa Mandioca e Fruticultura. Cruz das almas: EMBRAPA-CNPMF, 1990. $25 \mathrm{p}$.

AMERICAN INSTITUTE OF CANCER RESEARCH. 2006, 27 DE JUNHO. HEALTHY AND WISE A GUIDE TO THE SIMPLE LIFESTYLE STEPS THAT CAN HELP MINIMISE YOUR AND YOUR LOVED ONES' RISK OF CANCER.

BIANCHI, M. L. P., ANTUNES, L. M. G., Rev. NUtR., CAmpinas, 12(2): 123-130, MAIO/AGO., 1999.

BRASIL, Ministério da Saúde. Guia Alimentar para a população brasileira: Promovendo alimentação saudável. Brasília, 2006.

BREDA, Manuela Cristina. Fitoesteróis e os benefícios na prevenção de doenças: uma revisão. Universidade Federal do Rio Grande do Sul, Porto Alegre, p. 1-50, 2010.

CARPER J. ALIMENTOS: O MELHOR REMÉdIO PARA A BOA SAÚdE. 1995. RIO DE JANEIRO: Ed. CAMPUS. 632P.

CARVALHO, P. G. B., MACHADO, C. M. M., MORETTI, C. L., FONSECA, M. E. N. HORTALIÇAS COMO ALIMENTOS FUNCIONAIS. HORTIC.

BRAS. VOL.24 NO.4 BRASília OCT./DEC. 2006

CATALANI, L. A., KANG, E. M. S., DIAS, M. C. G., MACULEVICIUS, J. FIBRAS AlimentARES. ReV Bras Nutr CLIN 2003; 18(4):178-182.

Chandalia, M. Dietary treatment of Diabetes Mellitus. NeW ENGl. J. MeD., V.342, P.1392-1398, 2000.

CHAVES, M. O., BASSINELLO, P. Z., O feijão na alimentação humana. In: GONZAGA, A. C. de O. (Ed.). Feijão: o produtor pergunta, a Embrapa responde. 2. ed. rev. e atual. Brasília, DF: Embrapa, 2014. p. 15-23. 
Revista Multidisciplinar do Nordeste Mineiro, v.1, 2021/01

ISSN 2178-6925

COUTINHO, M. A. S., MUZITANO, M. F., COSTA, S. S., Flavonoides: Potenciais Agentes Terapêuticos para o Processo Inflamatório. Rev. Virtual Quim., 2009, 1 (3), 241-256.

FERREIRA, ICFR; ABREU, R. M.V. (2007). Stress oxidativo, antioxidantes e fitoquímicos. Bioanálise. ISSN 1646-1266. IV:2. p. 32-39 VALDUGA, E., TATSCH, P. O., TIGGEMANN, L., TREICHEL, H., TONIAZZO, G., ZENI, J., LUCCIO, M. PRODUÇÃO DE CAROTENOIDES: MICRORGANISMOS COMO FONTE DE PIGMENTOS NATURAIS. Quim. Nova, Vol. 32, No. 9, 2429-2436, 2009.

FERREIRA, S. R. G., ALIMENTAÇÃO, NUTRIÇÃo E SAÚDE: AVANÇOS E CONFLITOS DA modernidade, Cienc. Cult. vol.62 no.4 SÃo Paulo Oct. 2010.

GUIMARÃES, L. M., OLIVEIRA, D.S., Influência de uma alimentação saudável para longevidade e prevenção de doenças, Interciência \& Sociedade (ISSN: 2238-1295) - Vol. 3, N. 22014.

KEMPINSKI, E. M. B., VALERO, M. V., GUERRERO, A., ORNAGHI, V. A. C. P., MOTTIN, C., ...PRADO, I. N.. 2018. Preocupação deste século: longevidade com alimentação saudável. Pubsaúde, 1, a002. DOI:c

LIMA, ROMILDA DE SOUZA. CULTURA ALIMENTAR NO CONTEXTO DO SISTEMA FAMILIAR RURAL

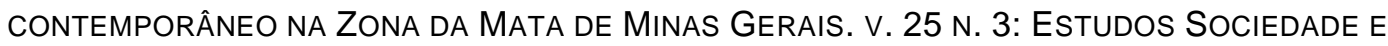
AGRICULTURA (OUTUBRO DE 2017 A JANEIRO DE 2018)

MARTIN, C. A., ALMEIDA, V. V., RUIZ, M. R., VISENTAINER, J. E. L., MATSHUSHITA, M., SOUZA, N. E., VISENTAINER, J. V., ÁcIDOS GRAXOS POLIINSATURADOS ÔMEGA-3 E ÔMEGA-6: IMPORTÂNCIA E OCORRÊNCIA EM ALIMENTOS. REV. NUtR. VOL.19 No.6 CAMPINAS Nov./DEC. 2006. 
Revista Multidisciplinar do Nordeste Mineiro, v.1, 2021/01

ISSN 2178-6925

MECHI, R., CANIATTI-BRAZACA, S. G., ARTHU, V. AVALIAÇÃO QUÍMICA, NUTRICIONAL E FATORES ANTINUTRICIONAIS DO FEIJÃO PRETO (PHASEOLUS VULGARIS L.) IRRADIADO. CIÊNC. TECnOL. Aliment. Vol.25 No.1 Campinas Jan./Mar. 2005

MIRA, G. S., GRAFT, H., CÂNDIDO, L. B. VISÃO RETROSPECTIVA EM FIBRAS ALIMENTARES COM ÊNFASE EM BETA-GluCANAS NO tRatamento do diabetes. BRAZ. J. Pharm.

SCI. VOL.45 NO.1 SÃo PAULO JAN./MAR. 2009

MORATOYA, E., CARVALHAES, G., WANDER, A., ALMEIDA, L. (2013). Mudanças no padrão de consumo alimentar no Brasil e no mundo. Revista de Política Agrícola. 22. 72-84.

NAVES, Maria Margareth Veloso. Características químicas e nUtricionais do arroz.

B.CEPPA, CURITIBA, V. 25, N. 1, P. 51-60, JAN./JUN. 2007

NOVELLO, D., FRANCESCHINI, P., QUINTILIANO, D. A., OST, P. R. OVO: CONCEITOS, ANÁlISES E CONTROVÉRSIAS NA SAÚdE HUMANA. ALAN V.56 N.4 CARACAS DIC. 2006

OLIVEIRA, D. DA S.; AQUINO, P. P.; RIBEIRO, S. M. R.; PROENÇA, R. P. DA C.; PINHEIROSANT'ANA, H. M. <b>Vitamina $C$, carotenoides, fenólicos totais e atividade antioxidante de goiaba, manga e mamão procedentes da Ceasa do Estado de Minas Gerais</b\&gt; - doi: 10.4025/actascihealthsci.v33i1.8052. Acta Scientiarum. Health Sciences, v. 33, n. 1, p. 89-98, 29 mar. 2011.

OLIVEIRA, M. E. B., GUERRA, N. B., BARROS, L. M., ALVES, R. E. Aspectos agronômicos e de qualidade do pequi. Fortaleza: Embrapa Agroindústria Tropical, 2008. 32 p. (Embrapa Agroindústria Tropical. Documentos, 113).

OLIVEIRA, M. N., SIVIERI, K., ALEGRO, J. H. A., SAAD, S. M. I., AsPeCtOS teCNOLÓGICOS DE ALIMENTOS FUnCIONAIS CONTENDO PROBIÓTICOS. REV. BRAS. CiENC.

FARM. VOL.38 NO.1 SÃo PAULO JAN./MAR. 2002. 
Revista Multidisciplinar do Nordeste Mineiro, v.1, $2021 / 01$

ISSN 2178-6925

PERALTA, I. \& GGUIMARÃES, M. \& ROCHA, H. \& MATEUS, T. (2017). Riscos e benefícios do consumo de carne vermelha. 11. 58.

SOUSA, A. P. B., LIMA, F. G. S., LIMA, A. PROPRIEDADES NUTRICIONAISDO MAXIXE E DO QUIABO. Rev. Saúde em foco, Teresina, v. 2, n. 1, art. 8, p. 113-129, jan./jul. 2015

THAMER, G. K., PENNA, A. L. B., CARACTERIZAÇÃO DE BEBIDAS LÁCtEAS FUNCIONAIS FERMENTADAS POR PROBIÓTICOS E ACRESCIDAS DE PREBIÓTICO. CIÊNC. TECNOL.

ALIMENT. VOL.26 NO.3 CAMPINAS JULY/SEPT. 2006

VENTURINI, K. S., SARCIENELLI, M. F., SILVA, L. C. Características da Carne de Frango. Universidade Federal do Espírito Santo - UFES. Pró-Reitoria de Extensão - P r o g r a $\mathrm{m}$ a Institucional de Extensão. Boletim Técnico - PIE-UFES:01307. Editado: 18.08.2007.

*VIDAL, A. M.; DIAS, D. O.; MARTINS, E. S. M.; OLIVEIRA, R. S.; NASCIMENTO, R. M. S.; CORREIA, M. das G. da S. A ingestão de alimentos funcionais e sua contribuição para a diminuição da incidência de doenças. Caderno de Graduação - Ciências Biológicas e da Saúde - UNIT - SERGIPE, [S. I.], v. 1, n. 1, p. 43-52, 2012.

WORLD HEALTH ORGANIZATION. "Diet, nutrition and the prevention of chronic diseases". Report of a Joint WHO/FAO Expert Consultation. Geneva: World Health Organization, 2003. [WHO Technical Report Series, 916]. 